\title{
Mechanical Harvesting of Table Olives: Harvest Efficiency and Fruit Quality
}

\author{
Isaac Zipori, Arnon Dag', and Yizhar Tugendhaft \\ Gilat Research Center, Agricultural Research Organization, M.P. Negev \\ 85280, Israel
}

\author{
Reuven Birger \\ Valley Farmer Center, P.O. Box 73, Migdal HaEmek, Israel
}

Additional index words. abscission agent, detachment force, Olea europaea, trunk vibrator

\begin{abstract}
Table olives are traditionally harvested manually. However, a shortage of agricultural workers and high labor costs have prompted the search for mechanical solutions. Mechanical harvesting of four cultivars of green table olive-Manzanilla, Hojiblanca, Souri, and Nabali Mouhassan-was compared with manual picking in terms of harvest efficiency and final product quality. Mechanical harvest methods were: trunk shaking with and without simultaneous rod beating and with and without the application of an abscission agent. Olives were immersed in a diluted $\mathrm{NaOH}$ solution in the field, transported to the processing plant, and subjected to commercial procedures processing. Application of an abscission agent resulted in inconsistent fruit-detachment force values and did not affect harvest efficiency. Mechanical harvest with rod beating reached high harvest efficiencies of $80 \%$ to $95 \%$, whereas the elimination of rod beating significantly reduced harvest efficiency. Final product quality of the mechanically harvested 'Hojiblanca', 'Souri'. and 'Nabali Mouhassan' was similar to that of their manually picked counterparts, whereas that of cv. Manzanilla was inferior to those picked manually. High harvest efficiencies can be obtained using trunk shakers and simultaneous rod beating but final product quality of the mechanically harvested olives depends on variety. In some, mechanical harvesting can be used safely; in others such as cv. Manzanilla, further work is required to obtain a good-quality final product.
\end{abstract}

World production of table olives (Olea europaea L.) has shown a steady increase for the last 20 years at an average rate of 100,000 $\mathrm{t} /$ year, reaching 2,526,000 tons in 2011-12 [International Olive Council (IOC), 2012]. In parallel, world consumption of table olives is rising as well. The major producing countries are Spain (21\%), Egypt (20\%), Turkey (16\%), Syria (7\%), and Morocco, Greece, and Italy, each producing $3 \%$ to $4 \%$ of the total world production (IOC, 2012).

Table olives are traditionally harvested manually. However, the shortage of manpower for harvesting on the one hand and increasing labor costs on the other (Birger et al., 2008; Ferguson et al., 2010; Vega Macias et al., 2005) have encouraged researchers and growers to test different mechanical-harvesting approaches for processing at a reasonable cost with low labor demand. Mechanical harvesting of table olives has been studied since 1975 (Ferguson et al., 2012; Vega Macias et al., 2005; Zion et al., 2011). However, use of this method is still very limited (Vega Macias et al., 2005). In contrast, mechanical harvesting of oil

\footnotetext{
Received for publication 9 Sept. 2013. Accepted for publication 25 Nov. 2013.

This research was funded by the Chief Scientist, Ministry of Agriculture, Israel.

We thank Bar Banegev Orchards, A. Livnat Orchards, Ashdot-Yaacov Orchards, and Bnei-Darom Industries for their cooperation and extensive help. ${ }^{1}$ To whom reprint requests should be addressed; e-mail arnondag@agri.gov.il.
}

olives has become a common practice in intensive orchards (Tous, 2011; Vossen, 2007). Most of the old, traditional oil olive orchards are still harvested manually, often aided by small-scale mechanical means such as rod beating or different types of combs operated by man and driven by electric, pneumatic, or two-tact engines. However, most of the oil olive orchards planted in the last few decades have been designed and shaped for mechanical harvesting by trunk shakers, overhead straddle-type harvesters, or canopycontact shakers (Ferguson et al., 2010).

The application of mechanical harvesting to table olives is more complex. Green table olives are harvested before the fruit reaches physiological maturity and therefore the force required to detach the fruit from the tree is high (Burns et al., 2008; Ferguson et al., 2005). This usually leads to low harvesting efficiency. In addition, mechanicalharvesting techniques generally result in a certain degree of fruit injury compared with traditional, manual harvesting (Ferguson, 2006; Rosa et al., 2009; Vega Macias et al., 2005). Severely injured olives cannot be used by the industry for processing as a result of consumer preferences. As a result, the use of mechanical harvesting for table olives is very limited and with increasing labor costs and decreasing availability of workers, the industry is in danger in some producing countries (Ferguson et al., 2012).

To alleviate the two major difficulties involved in the mechanical harvesting of table olives, i.e., harvesting efficiency and fruit injury, attempts have been made to use abscission agents to reduce fruit-detachment force (FDF), thereby increasing harvest efficiency (Martin, 1994) and reduce the vibration intensity used in mechanical harvesting, thereby reducing the percentage of injured fruit and the severity of the defects (Burns et al., 2008; Rosa et al., 2009; Vega Macias et al., 2005). Although various substances have been tested as abscission agents, the ones in current use are based on ethylene-releasing compounds (Hartman et al., 1970; Martin et al., 1981) or ethylene-releasing precursors (Banno et al., 1993; Birger et al., 2008; Goren and Huberman, 1998). The use of abscission agents has been shown to reduce FDF and increase harvest efficiency in many studies (Barranco et al., 2004; Ferguson et al., 2010), but it is accompanied, in many cases, by moderate to severe leaf drop (Martin et al., 1981). In addition, the efficiency of abscission agents is dependent on cultivar, temperature, and stress, so that in some cases, their application damages the tree canopy and in others, it does not affect FDF or harvest efficiency (Burns et al., 2008; Klein et al., 1978; Martin, 1994; Martin et al., 1981).

In the traditional manual harvesting of green table olives, the picked olives are usually stored in bins and transported to the processing plant shortly after harvest. After cleaning and sorting, the process at the plant depends on the desired final product. The most common product in table olives is the Spanishstyle green olive (Luh et al., 2005). At the processing plant, the olives are immersed in a solution of $\mathrm{NaOH}$ at a relatively high concentration $(2.5 \%)$ to remove bitterness. Once the solution has penetrated approximately twothirds of the distance between the skin and the pit, the olives are rinsed and stored in brine for fermentation. Other common products are California-style black ripe olives and Greekstyle naturally ripened olives (Luh et al., 2005). In Israel and neighboring countries, a product called "cracked olives" is very popular. In this process, the sorted olives are passed through a machine that presses the fruits to obtain flesh cracking. The cracked fruits are then kept in $11 \%$ brine solution, similar to Greek-style ripe olives (Luh et al., 2005). After fermentation, the olives are canned. This process is dependent on varietyit is not suitable for 'Manzanilla', for example, but is very suitable for the local cultivar Souri. This process is hereafter referred to as "Oriental processing."

The number of injured fruit in manually picked olives is usually small and injury intensity is generally not severe. The $\mathrm{NaOH}$ treatment conceals most of the light visible injuries. In mechanically harvested olives, the number of injured fruit is higher as is the intensity of the injuries (Ferguson et al., 2010). To minimize the number of non-cannable fruit, a preliminary field treatment has been proposed, consisting of immediate immersion of the harvested olives in a dilute solution of $\mathrm{NaOH}$, transportation in liquid to the processing plant, and completion of the process at the plant (Vega Macias et al., 2005). 
The current work evaluated mechanical harvesting of two common table olive products: Spanish-style green olives and cracked olives. Mechanical harvesting of four cultivars with trunk shakers (with and without rod beaters) was compared with manual picking during 2 successive years in the presence and absence of abscission agents. Harvest efficiency and fruit quality were assessed.

\section{Materials and Methods}

The study included the Spanish cvs. Manzanilla and Hojiblanca and the traditional local cvs. Souri and Nabali Mouhassan from three locations in Israel, as detailed in Table 1. The Revivim location is characterized by sandy-loam soil, arid climate, and drip irrigation with saline water. The coastal plain and the Jordan valley locations have a typical Mediterranean climate with clay-loam soil and drip irrigation with fresh water. In each location, two adjacent similar plots of 15 - to 20 -year-old trees were selected. One plot was sprayed with abscission agent $10 \mathrm{~d}$ before harvest and the other plot was not. The abscission agent was recommended by the Israeli Extension Service of the Ministry of Agriculture and was composed of Masikal ( $5 \%$ MKP $+1 \%$ urea; Haifa Chemicals, Israel) + Ethrel (48\% a.i., Agan Chemicals, Ashdod, Israel) $0.1 \%+$ Dimol surfactant (Drexel) $0.5 \%$ and was applied by means of an orchard blower sprayer at $2000 \mathrm{~L} \cdot \mathrm{ha}^{-1} 7$ to $10 \mathrm{~d}$ before harvest.

In each plot, high-yielding trees (trees in an "ON" year) were selected and treatments (Table 2) were assigned randomly, five trees (replicates) per treatment. Olives were harvested during September, at a ripening index of 1.0. A force gauge (Lutron, FG-5000A; MARK-10) was used to measure FDF on the day of harvest, before harvesting, on 100 fruits per tree. The gauge was equipped with a locally made fruit housing that permitted pulling of the fruit parallel to the pedicle and the fruit axis without exerting any shear component on the measurement. For trunk shaking, a linear trunk shaker (Model DT10, Dotan, Israel) attached to a tractor was used and the fruits were collected onto nets. Rod beating was performed manually with fiberglass rods, simultaneous with trunk shaking for 30 to $60 \mathrm{~s}$, by three to four workers per tree, each worker covering one-third to onefourth of the tree's canopy and using the same technique used in the mechanical harvest of oil olives. With the manually harvested trees, fruits were collected into baskets. With the mechanically harvested trees, fruits were cleaned of leaves with a blower and weighed.

To determine harvesting efficiency, the nets were re-extended after collection of the fruits harvested by trunk shaking, and the residual fruits were removed manually and by means of electric combs (Olivium, Pellenc, France). These fruits were also cleaned of leaves and weighed.

From each harvested tree, a subsample was sorted to size by a homemade manualsized grader and $1.5 \mathrm{~kg}$ of the $13-$ to $15-\mathrm{mm}$

Table 1. Cultivars included in the study and their respective geographical locations.

\begin{tabular}{|c|c|c|c|}
\hline Cultivar (tree/ha) & Origin of cultivar & Location & Coordinates \\
\hline Manzanilla (360-410) & Spain & Revivim (south) & Lat. $31^{\circ} 03^{\prime} 00^{\prime \prime} \mathrm{N}$, long. $34^{\circ} 42^{\prime} 51^{\prime \prime} \mathrm{E}$ \\
\hline Souri $(240-480)$ & Middle East & Revivim (south) & Lat. $31^{\circ} 02^{\prime} 58^{\prime \prime} \mathrm{N}$, long. $34^{\circ} 42^{\prime} 56^{\prime \prime} \mathrm{E}$ \\
\hline Nabali Mouhassan (360) & Middle East & Coastal plain & Lat. $31^{\circ} 47^{\prime} 56^{\prime \prime} \mathrm{N}$, long. $34^{\circ} 41^{\prime} 09^{\prime \prime} \mathrm{E}$ \\
\hline Hojiblanca (420) & Spain & Jordan valley & Lat. $32^{\circ} 38^{\prime} 32^{\prime \prime} \mathrm{N}$, long. $35^{\circ} 32^{\prime} 15^{\prime \prime} \mathrm{E}$ \\
\hline
\end{tabular}

Table 2. Description of treatments in the 2011 and 2012 experiments.

\begin{tabular}{|c|c|c|c|c|c|c|c|c|}
\hline \multirow[b]{2}{*}{ Harvest method ${ }^{z}$} & \multicolumn{4}{|c|}{2011} & \multicolumn{4}{|c|}{2012} \\
\hline & Manzanilla & Souri & Nabali & Hojiblanca & Manzanilla & Souri & Nabali & Hojiblanca \\
\hline$\overline{\mathrm{MP}}$ & $+^{\mathrm{y}}$ & + & + & + & + & + & + & + \\
\hline $\mathrm{TS}+\mathrm{RB}+\mathrm{AA}$ & + & + & + & + & + & + & + & + \\
\hline $\mathrm{TS}+\mathrm{RB}-\mathrm{AA}$ & - & + & - & - & + & + & + & + \\
\hline $\mathrm{TS}-\mathrm{RB}+\mathrm{AA}$ & + & + & + & - & + & + & - & - \\
\hline
\end{tabular}

${ }^{\mathrm{z}} \mathrm{MP}=$ manual picking; $\mathrm{TS}=$ trunk shaking; $\mathrm{RB}=$ rod beating with polyvinyl chloride rods; $\mathrm{AA}=$ abscission agent spray.

$\mathrm{y}_{+}=$Available data $-=$no available data .

fraction was collected and immediately put in a plastic container in $0.5 \%$ (2011) or $1 \%$ (2012) food-grade $\mathrm{NaOH}$ solution. This procedure was used for the cultivars Manzanilla, Nabali, and Hojiblanca. Cultivar Souri fruit were cracked immediately after harvest by means of a drum cracker and put in containers with an $11 \% \mathrm{NaCl}$ solution (Oriental processing), the commercial practice for this cultivar. The containers were tightly closed and kept in the shade. In the afternoon, the samples were transported to the processing plant, where the $\mathrm{NaOH}$ solution was replaced with the same solution at a concentration of $2.5 \%$ until it had penetrated two-thirds of the fruit pulp. The olives were then rinsed with water and then again with a $0.8 \% \mathrm{HCl}$ solution to remove all residual $\mathrm{NaOH}$ and afterward were kept in brine for fermentation. In the cv. Souri samples (Oriental processing), the solution was not changed.

Lactic acid level, $\mathrm{pH}$, and salt content in the brine were monitored during fermentation. The olives were considered ready for packing when these values reached levels of $4.0 \%$ to $4.5 \%, 1$ and $5.5 \%$ to $6.5 \%$, respectively. At this stage, their quality was determined by sampling $\approx 300 \mathrm{~g}$ of olives and sorting them into three categories: heavily injured, slightly injured, and not injured. These categories were selected because in commercial processing, heavily injured fruits are discarded, whereas slightly injured fruits are considered suitable for canning. Each category was weighed separately and its fraction of the total weight was calculated.

Results were statistically analyzed using JMP software (JMP5.0.1; SAS Inc., Cary, NC) using the Tukey-Kramer $t$ test.

\section{Results}

The effect of applying abscission agent on FDF, measured just before harvest, is presented in Table 3. In 2011, the FDF in the trees treated with abscission agent was significantly lower than in nontreated trees. However, in 2012, except the 'Hojiblanca', there was no significant difference between treated and nontreated trees.

Harvest efficiency in the different harvest treatments is presented in Table 4. Manual picking always showed $100 \%$ efficiency. In the mechanized harvest, the highest efficiency was obtained when trees were harvested by trunk shaking and rod beating with fiberglass rods. The application of abscission agents did not affect harvest efficiency significantly. However, harvesting the trees by trunk shaking without rod beating resulted in a strong, significant decrease in harvest efficiency despite the application of abscission agent.

The relations between fruit removal force and harvest efficiency are presented in Figure 1. Each point represents the average harvest efficiency of five replicate trees and the average FDF measured on the same trees. When rod beating was used, harvest efficiency reached high values $(80 \%$ to $100 \%)$ regardless of the removal force measured. When rod beating was not used, harvest efficiency increased from $45 \%$ to $75 \%$ with a parallel decrease in removal force from $300 \mathrm{~g}$ to $100 \mathrm{~g}$.

The effect of harvest method on fruit quality is presented in Table 5. The numbers indicate the percentage of heavily injured fruits out of the total yield, assuming that the slightly injured fruits would be considered suitable for marketing together with the noninjured ones. In most cases, $\approx 50 \%$ of the harvested fruit was classified as non-injured.

Manual picking of $\mathrm{cv}$. Manzanilla fruit yielded $8.2 \%$ (2011) and $17.5 \%$ (2012) of severely injured fruits. These values are a slightly above the acceptable commercial values of $5 \%$ to $10 \%$ but still within reasonable limits. In 2011, the percentage of severely injured fruits from both mechanical harvesting methods was significantly higher than from the manual harvest. In 2012, these values were much lower, approximately half those of 2011, with the difference being significant only between manual harvest and mechanical harvesting without rod beating. There was no significant difference between the percentage of severely injured fruit from the manual harvest and mechanical harvesting with rod beating. The application of abscission agents did not affect fruit quality.

The percentage of heavily injured fruits in cv. Nabali Muhassan was relatively low and similar for manual harvesting and the tested methods of mechanical harvesting in both 
Table 3. Effect of application of abscission agent on fruit detachment force.

\begin{tabular}{|c|c|c|c|c|}
\hline \multirow[b]{3}{*}{ Cultivar } & \multicolumn{2}{|c|}{2011} & \multicolumn{2}{|c|}{2012} \\
\hline & \multicolumn{4}{|c|}{ Treatment } \\
\hline & $\begin{array}{l}\text { With abscission } \\
\text { agent }(\mathrm{g})\end{array}$ & $\begin{array}{c}\text { Without abscission } \\
\text { agent }(\mathrm{g})\end{array}$ & $\begin{array}{l}\text { With abscission } \\
\text { agent }(\mathrm{g})\end{array}$ & $\begin{array}{c}\text { Without abscission } \\
\text { agent }(\mathrm{g})\end{array}$ \\
\hline Manzanilla & $108 b^{z}$ & $199 \mathrm{a}$ & $432 \mathrm{~A}$ & $397 \mathrm{~A}$ \\
\hline Souri & $220 \mathrm{~b}$ & $264 \mathrm{a}$ & $379 \mathrm{~A}$ & $416 \mathrm{~A}$ \\
\hline Nabali & $303 \mathrm{~b}$ & $348 \mathrm{a}$ & - & - \\
\hline Hojiblanca & $378 \mathrm{~b}$ & $564 \mathrm{a}$ & $267 \mathrm{~A}$ & $598 \mathrm{~B}$ \\
\hline
\end{tabular}

${ }^{\mathrm{z}}$ Data were statistically analyzed for each cultivar and year separately. Same letters indicate no significant difference between treatments (Tukey-Kramer, $P<0.05$ ).

Table 4. Harvest efficiency (percent of fruit removed by harvest method out of total yield) of different harvesting treatments.

\begin{tabular}{|c|c|c|c|c|c|c|c|c|}
\hline \multirow[b]{2}{*}{ Treatment $^{\mathrm{z}}$} & \multicolumn{4}{|c|}{2011} & \multicolumn{4}{|c|}{2012} \\
\hline & Manzanilla & Souri & Nabali & $\overline{\text { Hojiblanca }}$ & Manzanilla & Souri & Nabali & $\overline{\text { Hojiblanca }}$ \\
\hline$\overline{\mathrm{MP}}$ & $100.0 \mathrm{a}^{\mathrm{y}}$ & $100.0 \mathrm{a}$ & $100.0 \mathrm{a}$ & $100.0 \mathrm{a}$ & $100.0 \mathrm{a}$ & $100.0 \mathrm{a}$ & $100.0 \mathrm{a}$ & $100.0 \mathrm{a}$ \\
\hline $\mathrm{TS}+\mathrm{RB}+\mathrm{AA}$ & $94.3 \mathrm{a}$ & $74.6 \mathrm{a}$ & $92.4 \mathrm{a}$ & $96.0 \mathrm{a}$ & $89.3 \mathrm{a}$ & $100.0 \mathrm{a}$ & $99.5 \mathrm{a}$ & $93.8 \mathrm{a}$ \\
\hline $\mathrm{TS}+\mathrm{RB}-\mathrm{AA}$ & - & $78.4 \mathrm{a}$ & - & - & $100.0 \mathrm{a}$ & $100.0 \mathrm{a}$ & $100.0 \mathrm{a}$ & $90.2 \mathrm{a}$ \\
\hline $\mathrm{TS}-\mathrm{RB}+\mathrm{AA}$ & $76.0 \mathrm{~b}$ & $58.5 \mathrm{~b}$ & $45.3 \mathrm{~b}$ & - & $99.5 \mathrm{a}$ & $87.8 \mathrm{~b}$ & - & - \\
\hline
\end{tabular}

${ }^{\mathrm{z}} \mathrm{MP}=$ manual picking; $\mathrm{TS}=$ trunk shaking; $\mathrm{RB}=$ rod beating with polyvinyl chloride rods; $\mathrm{AA}=$ abscission agent spray.

${ }^{y}$ Data were statistically analyzed for each cultivar and year separately. Same letters indicate no significant difference between treatments (Tukey-Kramer, $P<0.05$ ).

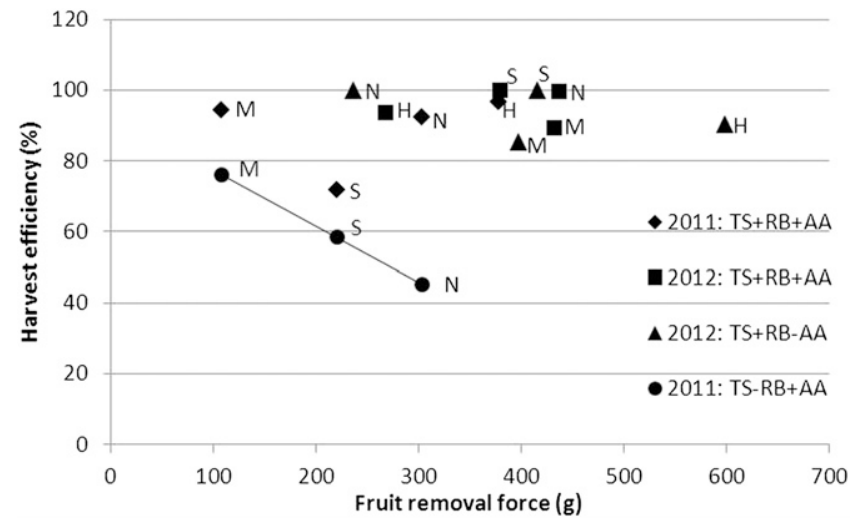

Fig. 1. The relations between harvest efficiency and fruit removal force.

Table 5. Effect of harvest method on fruit quality (percent of fruit with severe injury).

\begin{tabular}{|c|c|c|c|c|c|c|c|c|}
\hline \multirow[b]{2}{*}{ Harvest method ${ }^{\mathrm{z}}$} & \multicolumn{4}{|c|}{2011} & \multicolumn{4}{|c|}{2012} \\
\hline & Manzanilla & Souri & Nabali & $\overline{\text { Hojiblanca }}$ & Manzanilla & Souri & Nabali & $\overline{\text { Hojiblanca }}$ \\
\hline$\overline{\mathrm{MP}}$ & $8.2 \mathrm{a}^{\mathrm{y}}$ & $0.0 \mathrm{a}$ & $28.4 \mathrm{a}$ & $50.8 \mathrm{a}$ & $17.5 \mathrm{~b}$ & $17.2 \mathrm{a}$ & $25.3 \mathrm{a}$ & $8.7 \mathrm{~b}$ \\
\hline $\mathrm{TS}+\mathrm{RB}+\mathrm{AA}$ & $61.9 \mathrm{~b}$ & $0.0 \mathrm{a}$ & $20.3 \mathrm{a}$ & $77.0 \mathrm{~b}$ & $30.1 \mathrm{ab}$ & $16.8 \mathrm{a}$ & $24.4 \mathrm{a}$ & $15.2 \mathrm{ab}$ \\
\hline $\mathrm{TS}+\mathrm{RB}-\mathrm{AA}$ & - & $0.0 \mathrm{a}$ & - & - & $26.6 \mathrm{ab}$ & $16.2 \mathrm{a}$ & $21.9 \mathrm{a}$ & $28.2 \mathrm{a}$ \\
\hline $\mathrm{TS}-\mathrm{RB}+\mathrm{AA}$ & $76.2 \mathrm{~b}$ & $0.0 \mathrm{a}$ & $32.8 \mathrm{a}$ & - & $44.0 \mathrm{a}$ & $15.3 \mathrm{a}$ & - & - \\
\hline
\end{tabular}

${ }^{\mathrm{z}} \mathrm{MP}=$ manual picking; $\mathrm{TS}=$ trunk shaking; $\mathrm{RB}=$ rod beating; $\mathrm{AA}=$ abscission agent spray.

yata were statistically analyzed for each cultivar and year separately. Same letters indicate no significant difference between treatments (Tukey-Kramer, $P<0.05$ ).

2011 and 2012 with slightly lower values in 2012.

In 2011, cv. Hojiblanca reached high values of heavily injured fruits with both manual and mechanical harvesting. In 2012, these values were much lower. The manually picked fruit generally had a lower injury level than the mechanically harvested ones; with rod beating, these values did not differ significantly from the manual harvest, but this difference was significant without rod beating.

As already noted, cv. Souri was treated differently from the other three cultivars tested. Fruits were cracked after harvest and put directly in $11 \%$ brine, which is the the mechanical harvest of table olives is still very limited, requiring extensive study to reach a widely applicable procedure. Mechanical harvesting of table olives has been studied using trunk shakers (Birger et al., 2008) and canopy-contact harvesters (Ferguson et al., 2010; Rosa et al., 2009), and the usual approach is to use the same equipment used in the mechanical harvesting of oil olives. A few attempts have been made to develop specific equipment for table olive harvesting (Ferguson et al., 2012), but these are the exception.

In most cases, harvest efficiency of the tree shaking + rod beating treatments was high (Table 4), above the economically feasible $80 \%$ threshold (Ferguson et al., 2010). The harvest efficiency values presented in Table 4 were close to those obtained in oil olives (Shire et al., 2009; Zion et al., 2011), which are harvested at a more advanced stage of ripening and are therefore more easily detached from the tree and higher than those reported for table olives by Vega Macias et al. (2005). These high harvest efficiencies are the combined result of high-energy trunk shakers, rod beating, and limited tree volume, allowing the vibration to reach all parts of the tree. An exception was cv. Souri in 2011, where harvest efficiency of tree shaking + rod beating was $71.6 \%$ - too low for commercial purposes. This might have been because this cultivar was harvested too early in 2011.

The economic aspect of mechanical harvest is significant. Under the Israeli conditions, the harvest cost of manually picked olives is $\approx \$ 0.37 / \mathrm{kg}$, whereas the cost for mechanically picked olives is $\$ 0.17 / \mathrm{kg}$, which is less than $50 \%$ compared with manual picking. This alone makes mechanical harvest economically feasible, even if harvest efficiency is slightly lower compared with manual picking. Fruit abscission agents as a means of increasing mechanical olive harvest efficiency and reducing the energy required to detach the fruit from the pedicle have been investigated for several decades now (Burns et al., 2008; Martin, 1994; Rosa et al., 2009). In most cases, the effect of the abscission agents is characterized by measuring FDF (Ben-Tal, 1992; Burns et al., 2008; Ferguson et al., 2010, 2012; Lavee et al., 1982). Little has been published on the effect of abscission agent application relative to both FDF and harvest efficiency. Birger et al. (2008) and Tous et al. (1995) found a correlation between FDF and harvest efficiency in oil olives harvested at an advanced stage of ripening, but not in green table olives. Lavee et al. (1982) showed that harvesting efficiency and leaf drop are varietysensitive, and Klein et al. (1978) demonstrated the sensitivity of the system to irrigation practices and temperature. In the present study, the application of an abscission agent before harvest resulted in an inconsistent FDF response (Table 3), as also found by Avidan et al. (2008), and no response with respect to harvest efficiency (Table 4). The only exception was when rod beating was not used (Fig. 1). In this case, harvest efficiency increased with the decrease in FDF. This indicates that FDF can serve as a measure 
for potential harvest efficiency only when rod beating is not to be used. Harvest efficiency without rod beating was significantly lower than that with rod beating (Table 4).

From the current study, it seems that fruit quality is very strongly dependent on cultivar and is probably related to skin and pulp properties. From the results obtained so far (Table 5), it seems that cvs. Nabali Mouhassan and Hojiblanca for traditional Spanish processing, and cv. Souri for Oriental processing, can be harvested mechanically quite successfully, even at the cost of a slightly higher percentage of injured fruit. However, for the major table cv., Manzanilla, additional effort is required to improve fruit quality. Ferguson et al. (2010) found high rates of cannable fruits for mechanically harvested 'Manzanilla' olives (96\%), but they looked at blackened, not green table olives. The blackening process is likely to conceal most of the injuries caused by mechanical harvesting.

In 2011, high rates of heavily injured fruit were found for cv. Hojiblanca (Table 5). The fact that high rates were also found in the manually picked olives indicates that the cause of the injury was not the mechanical harvesting. In fact, most of the fruits that were classified as heavily injured had no symptoms of mechanical damage, but rather large brown-reddish stains that were observed on the fruit skin at the end of the process, when fruits were ready for canning. The reason for the appearance of these stains in not known, and their amount and intensity almost completely disappeared after exposing the fruits to air during final sorting and canning.

To obtain high-quality olives from mechanical harvesting, an immediate postharvest treatment can be applied, preferably in the field (Vega Macias et al., 2005). Here we took the most commonly used approach, i.e., immersion of the olives in a diluted solution of $\mathrm{NaOH}$ in the field immediately after harvest, and continuation of the process at the processing plant. Other procedures such as the use of a cold sodium metabisulfite solution (Segovia-Bravo et al., 2012), which improved the quality of mechanically harvested 'Manzanilla' olives, might be a promising direction.

In general, fruit quality was lower in the 2011 vs. 2012 harvest. This can be attributed to the higher concentration of $\mathrm{NaOH}$ used in 2012 (1\%) compared with $2011(0.5 \%)$. However, this higher concentration for the field treatment means that the harvested fruit must reach the processing plant faster so that the olives will not be overdigested. The highest percentage of heavily injured fruit was obtained in the tree shaking with no rod beating + abscission agent treatment, which further emphasizes the importance of rod beating. We assume that when rod beating is not used, more energy has to be invested in tree shaking, which leads to more severely injured fruit when they either hit the tree branches or each other. In rod beating, the rods usually hit the branches and not the fruits themselves, so the latter incur less damage.

The results presented in Table 4 indicate that in many cases, table olives can be harvested mechanically using the same equipment and methods used for oil olives. High harvest efficiencies are reached when trunk shaking is accompanied by rod beating. The effect of abscission agents on harvest efficiency is negligible and in most cases inconsistent, and they can probably be omitted, especially when cost-benefit considerations are taken into account together with the potential damage from defoliation (Ben-Tal and Lavee, 1976; Tous et al., 1995).

\section{Conclusion}

Mechanical harvesting of green table olives can be commercially efficient using today's equipment. The use of abscission agents is not mandatory for obtaining high harvest efficiencies, but the use of rod beating seems to be. Fruit quality of mechanically harvested table olives strongly depends on cultivar. 'Nabali Mouhassan' or 'Hojiblanca' can be harvested mechanically using the present knowledge in postharvest field treatments. In the case of 'Manzanilla', postharvest field treatment must be improved to attain a higher percentage of cannable fruits.

\section{Literature Cited}

Avidan, B., Y. Meni, R. Birger, and R. Shire. 2008. Loosening fruit pedicle in olives to improve harvest efficiency. Alon HaNotea 62:474-477 [in Hebrew].

Banno, K., G.C. Martin, and R.M. Carlson. 1993. The role of phosphorous as an abscissioninducing agent for olives and fruit. J. Amer Soc. Hort. Sci. 118:599-604.

Barranco, D., O. Arquero, C. Navarro, and H.F. Rapoport. 2004. Monopotassium phosphate for olive fruit abscission. HortScience 39:13131314.

Ben-Tal, Y. 1992. Quantification of ethephon requirements for abscission in olive fruits. Plant Growth Regulat. 11:397-403.

Ben-Tal, Y. and S. Lavee. 1976. Ethylene influence on leaf and fruit detachment in 'Manzanillo' olive trees. Sci. Hort. 4:337-344.

Birger, R., F. Abd-El Hadi, A. Ronen, E. Cohen, Y. Ankorion, A. Najjar, and J. Moreno. 2008. Olive HarvestVant, a new harvest-aid formulation for improving fruit abscission and mechanical harvesting. Acta Hort. 791:257-263.

Burns, J.K., L. Ferguson, K. Glozer, W.H. Krueger, and R.C. Rosecrance. 2008. Screening fruit loosening agents for black ripe processed table olives. HortScience 43:1449-1453.

Ferguson, L. 2006. Trends in olive fruit handling previous to its industrial transformation. Grasas Aceites 57:9-15.

Ferguson, L., K. Klonsky, and G.C. Martin. 2005. The olive harvest, p. 135-140. In: Sibbett, G.S., L. Ferguson, J.L. Coviello, and M. Lindstrand (eds.). Olive production manual. University of California Agricultural and Natural Resources Publication 3353.

Ferguson, L., J. Miles, U. Rosa, S. Castro-Garcia, W.H. Krueger, E.J. Ficthner, N. O'Conell, and
P.M. Vossen. 2012. Developing mechanical harvesting for California black ripe table olives. West Coast Olive Guide, July/Aug. 2012 issue, JCS marketing publication, p. 10-14. <http:// www.wcolive.com>.

Ferguson, L., U.A. Rosa, S. Castro-Garcia, S.M. Lee, J.X. Guinard, J. Burns, W.H. Krueger, N.V. O'Conell, and K. Glozer. 2010. Mechanical harvest of California table and oil olives. Adv. Hort. Sci. 24:53-63.

Goren, R. and M. Huberman. 1998. Phosphorusinduced leaf in detached shoots of olive and Citrus. J. Amer. Soc. Hort. Sci. 123:545-549.

Hartman, H.T., A. Tombesi, and J. Whisler. 1970. Promotion of ethylene evolution and fruit abscission in the olive by 2-chloroethanephosphonic acid and cycloheximide. J. Amer. Soc. Hort. Sci. 95:635-640.

IOC. 2012. Table olives. Nov. 2012. <http:// www.internationaloliveoil.org $>$.

Klein, I., E. Epstein, S. Lavee, and Y. Ben-Tal. 1978. Environmental factors affecting ethephon in olive. Sci. Hort. 9:21-30.

Lavee, S., B. Avidan, and Y. Ben-Tal. 1982. Effect of fruit size and yield on the fruit-removalforce within and between olive cultivars. Sci. Hort. 17:27-32.

Luh, B.S., L. Ferguson, A. Kader, and D. Barrett. 2005. Processing California olives, p. 145-155. In: Sibbett, S.T., L. Ferguson, J.L. Coviello, and M. Lindstrand (eds.). Olive production manual. 2nd Ed. University of California Agricultural and Natural Resources Publication 3353.

Martin, G.C. 1994. Mechanical olive harvest: Use of fruit loosening agents. Acta Hort. 356:134 138.

Martin, G.C., S. Lavee, and G.S. Sibbett. 1981. Chemical loosening agents to assist mechanical harvest of olive. J. Amer. Soc. Hort. Sci. 106: 325-330.

Rosa, U., L. Ferguson, C. Gliever, K. Glozer, C. Crisosto, B. Krueger, R. Diaz-Silva, D. Pursell, J. Galbraith, D. Smith, S. Castro-Garcia, and J. Burns. 2009. Fruit injury from mechanical harvester for California black ripe processed table olive. Acta Hort. 824:337-348.

Segovia-Bravo, K.A., P. Garcia-Garcia, A. LopezLopez, and A. Garrido-Fernandez. 2012. Effect of inert atmosphere on postharvest browning of Manzanilla olives and optimization by response surface methodology of the aqueous treatments. J. Food Sci. 77:s194-s201.

Shire, R., R. Birger, O. Birger, and B. Avidan. 2009. Experiment in fruit pedicle loosening in olives. Alon HaNotea 63:976-978 [in Hebrew].

Tous, J. 2011. Olive production systems and mechanization. Acta Hort. 924:169-184.

Tous, J., J. Lloveras, and A. Romero. 1995. Effect of ethephon spray treatments on mechanical harvesting and oil composition of 'Arbequina' olives. J. Amer. Soc. Hort. Sci. 120:558-561.

Vega Macias, V.A., L. Navarro Rejano, J.P. Guzman Diaz, C. Navarro Garcia, A. Higinio Sanchez, and J.M. Diaz Montero. 2005. Recoleccion mecanizada de la aceituna de 'verdeo.' Agricultura 874:376-379.

Vossen, P. 2007. Olive oil: History, production and characteristics of the world's classic oils. HortScience 42:1093-1100.

Zion, B., A. Bechar, R. Regev, N. Shamir, A. Weissblum, Y. Zipori, and A. Dag. 2011. Mechanical harvest of olives-An operations study. Isr. J. Plant Sci. 59:71-84. 